\title{
The Construction of SPOC Learning Model in a Mixed Perspective
}

\author{
Xin Sui \\ College of Humanities and Sciences \\ Northeast Normal University \\ Changchun, 130117, P.R.China \\ suixin1997@126.com
}

\author{
Xiaomei Wang* \\ College of Humanities and Sciences \\ Northeast Normal University \\ Changchun, 130117, P.R.China \\ 17048972@qq.com \\ Corresponding author
}

\begin{abstract}
Recent years, colleges and universities have made use of high quality MOOC resources to constantly try to reform the teaching. But MOOC lacks face-to-face communication between teachers and students, and students do not have a comple te classroom experience. SPOC is private online course in which students can learn both online and SPOC, and communicate with their teachers. This paper puts forward the design and implementation of SPOC mixed teaching model, and evaluates the teaching effect. It is hoped that we can promote the SPOC teaching model, and then it can promote the students' active learning conscious ness so as to improve the teaching effect.
\end{abstract}

Keywords-MOOC; reform; SPOC; mixed teaching model

\section{INTRODUCTION}

With the popularization of information technology, the Internet has a great impact on the field of education. The progress of science and technology has resulted in the innovation of technology and ideas. Great changes have taken place in the field of education. From the open sharing of educational resources to the diversified teaching mode, the development of network education has entered a mature stage.

In 2012, the rapid development of MOOC, Coursera, Udacity, edX and other platforms have been established. The world's well-known universities and platform providers have launched fierce competition for the share of the education field. The New York Times called 2012 'the year of MOOC".

In the process of teaching practice, there are some problems in the MOOC mode. The management mechanism of MOOC teaching mode is not perfect, resulting in higher enrollment rate and low success rate. Between teachers and students, students' teaching activities are completed in the virtual network. Teachers' 'teaching" as the purpose of teaching, instead of students' "active learning" as the purpose.

In 2013, Professor Armando•Fox of California at Berkeley University put forward the concept of SPOC. Wikipedia SPOC

Fund Project: Jilin Province Education Science " Thirteenth Five - year Plan" 2016 Key Topics " Research on Flip Classroom Teaching Mode Based on MOOC + SPOC " ( project approval number: ZD 16071); Jilin Provincial Higher Education Association 2016 Higher Education Research Key Topic " Access Database Technology and Application Based on SPOC" Course Mix Research on Teaching Mode " ( project number: JGJX2016B27 ) results;2016 Jilin Higher Education Reform Research project " Research and Practice of SPOC Teaching Mode" research results. Jilin Provincial Department of education "13th Five-Year" science and technology research project "Design and Research of Private Cloud Construction of Enterprises", Project No.: JJKH20181306KJ. will be interpreted as: students in the local version of MOOC. [1] Professor Hoffmann considers that SPOC=MOOC + Classroom and shows that SPOC is a mixed teaching model of integrating physical and online education. [2]

Harvard University Professor Lu Robert put forward that SPOC has replaced the MOOC.SPOC is entering the post MOOC era. [3]

\section{THE DESIGN AND PRACTICE OF SPOC MIXED TEACHING MODEL}

SPOC is small private online course; small and private are compared with massive and open of MOOC. Small generally refers to the scale in the dozens to hundreds of people. Private refers to the limited access conditions for learning, to meet certain requirements before they can join the course of learning. [4]

The organic combination of the two ways of face-to-face classroom learning and online learning is the initial definition of a mixed learning model. [5] With the practice and development of learning, the mixed learning model is divided into three levels. The first level is the mixing of simple forms, the mixing of teaching and learning, and the integration of the teachers' professors and the students' learning.

The second level is the combination of two forms of classroom learning and online learning. The third level is the combination of knowledge learning and the application of knowledge migration. [6]

SPOC blended teaching mode is deep learning, the mix of learning and learning. Not only requires students to complete the construction of knowledge, but also for knowledge transfer and application. [7]

SPOC is an organic combination of MOOC and traditional campus, the basic form is online using MOOC teaching video, offline using entity classroom teaching. SPOC is a solution for small, specific groups of people to change the status of traditional education through MOOC. [8]

SPOC comes from MOOC, and SPOC is in order to solve many problems existing in the teaching practice of MOOC. SPOC solves these problems by limiting access conditions, reducing the size of the students, and enhancing the role of teachers. [9] 
SPOC is a branch of MOOC, which limits the access conditions of students and is qualified to join the SPOC course only if the application conditions are satisfied. The goal of SPOC is to achieve the best possible integration of MOOC and traditional classroom teaching as far as possible. [10]

\section{A. Design of Teaching Process}

The design of the teaching process is the bridge and link between the teaching theory and the practice of teaching. The design of the teaching process is the process of defining the problems, determining the cause of the problem and implementing the intervention measures. The essence of teaching design is the process of solving a problem. [11]

\section{B. Analysis of Learning Goals}

Teachers design learning objectives according to the syllabus, and determine the students' learning effects that should be achieved through learning. The teacher guide the teaching activities and teaching evaluation. In the course of SPOC teaching practice, the whole learning goal is given, and then the learning objectives of each part are refined to ensure the smooth completion of the whole teaching process. [12]

The teachers according to the learning objectives, professional characteristics, the design of teaching content, determine which teaching content for online teaching, which content is suitable for face-to-face teaching.

Professor Armando-Fox pointed out that SPOC should be used in classroom teaching. The teachers can expand the teaching method, improve students' throughput, participation, to further improve the students' level of knowledge. [13]

\section{Analysis of Learning Objects}

The subject of learning is the main body of the teaching activities, and the analysis of the learning object is helpful for the learners to learn better. The initial ability analysis of learning objects is mainly to understand what abilities and preparatory knowledge that learners already possess, whether these preparatory knowledge is beneficial to new learning.

In the course of learning, each learner embodies the emotional factors of individual, that is, the learning style of the learner. When the learners get in touch with the new learning environment, what is the way to interact with the learning environment is the function of the learning style.

The restrictive access conditions of SPOC enable some learners to enter learning. Some people can only access limited resources by the listener's identity, and cannot participate in more teaching experience. Only a limited number of learners can enjoy all the resources and participate in more teaching activities, and they will cherish the opportunity to learn more.

\section{Design of Learning Process}

1) Pre class activity design: Teachers make basic knowledge points and make SPOC teaching video. Each knowledge point is a teaching video, and a teaching video is 10 minutes in length, and a slightly difficult point of knowledge can be 15 minutes. SPOC teaching video mainly focuses on the key and difficult points, and the simple teaching video is not made into teaching video.
In the pre class stage, the teacher arranges the students' learning task, and the students watch the SPOC teaching video through the line. Students can watch the teaching video repeatedly according to their own mastery, and the key and difficult points can be replayed.

This can meet the students of different learning bases. The students have finished the SPOC teaching video, and they also have to complete the related exercises and tests after each class.

Students can discuss online through the SPOC platform and share the problems with their classmates and teachers to get a better learning experience.

2) Classroom activity design: Before the classroom teaching, the students take groups as units, report on the teaching content on the line, and sort out and summarize the knowledge points. Through group discussion, group discussion, teachers' discussion with students, students' opinions and doubts about their knowledge are published, and students cooperate to explore problems, instead of arranging teaching activities in a nonlinear way.

The traditional teaching methods used to arrange teaching in a linear way. Under the SPOC teaching mode, the teacher will not arrange the teaching content according to the way of teaching in the past.

A relatively independent knowledge module is divided into several small tasks corresponding to knowledge points. Each small task provides original design and operation material, and students can learn from any knowledge point. In the teaching process, according to the curriculum requirements, we should follow the basic steps of "task analysis task completion task", so as to improve students' interest and enthusiasm in learning, which not only completes the learning of curriculum knowledge points, but also improves their autonomous learning ability and practical ability.

Teachers should pay more attention to the interaction between teachers and students in class. To solve the challenging problems encountered by students targeted counseling and answering questions. In classroom teaching, teachers arrange the whole teaching activities to drive students with low learning enthusiasm to take the initiative to learn. Face - to - face discussion to better mobilize online learning.

The study of mixed and inquiring teaching mode is explored, and online learning is combined with offline counselling and answering questions.

The teacher shows students' works in class, summarizes the problems exposed by students in learning process, and individualized knowledge for every student, teaching students in accordance with their aptitude.

The whole learning process should pay more attention to the learners. The control of the learning process should be effectively interacted, and every interaction should have the contents of supervision, interaction, incentive and feedback.

3)Consolidation after class: After - class practice is to consolidate and strengthen the pre-class and in-class content. 
Students complete after-class exercises as required by the teacher, including multiple choice questions, fill in empty questions and short answer questions, submit homework online platform, the system automatically complete scoring and feedback. Students can check the gap, to further understand the knowledge.

SPOC teaching pays more attention to the organic combination of online teaching and offline teaching. Teachers can better combine teaching with learning in practical teaching. SPOC is helpful to the emotional communication between teachers and students through physical classroom teaching with personal guidance for students. SPOC provides students with a better in-depth learning experience. SPOC allows teachers to better grasp the whole classroom order, can provide students with different learning progress, learners can fully reflect the individual differences.

SPOC innovates the teaching model and redefines the role of the teacher. The teacher really becomes the master of the curriculum. Before class, teachers are the integrators and learners of teaching resources. In the classroom, teachers provide individualized guidance to the students to solve the problems encountered.

\section{EVALUATION OF TEACHING EFFECT}

In the three aspects of teaching design, teaching implementation and teaching effect, we evaluated the mixed teaching mode of SPOC based university computer basic course.

Conduct an evaluation. SPOC evaluation is diversified and personalized. The evaluation adopts the combination of process evaluation and final evaluation, and quantitative evaluation and qualitative evaluation to establish an effective and scientific evaluation system.

In January 2018, a total of 100 questionnaires were issued to students and 100 questionnaires were collected, with an effective rate of $100 \%$. The results of the investigation are shown in TABLE I as follows.

TABLE I. STUDENT SATISFACTION

\begin{tabular}{|l|l|l|l|}
\hline & good & commonly & difference \\
\hline $\begin{array}{l}\text { The degree of acceptance of the } \\
\text { mixed teaching model }\end{array}$ & $90 \%$ & $6 \%$ & $4 \%$ \\
\hline $\begin{array}{l}\text { The connection between the } \\
\text { mixed teaching model and the } \\
\text { traditional teaching }\end{array}$ & $92 \%$ & $5 \%$ & $3 \%$ \\
\hline $\begin{array}{l}\text { Satisfaction of teaching } \\
\text { resources }\end{array}$ & $91 \%$ & $4 \%$ & $5 \%$ \\
\hline $\begin{array}{l}\text { Knowledge memo ry and } \\
\text { understanding }\end{array}$ & $89 \%$ & $10 \%$ & $1 \%$ \\
\hline Communication ability & $90 \%$ & $7 \%$ & $3 \%$ \\
\hline Improving learning efficiency & $87 \%$ & $9 \%$ & $4 \%$ \\
\hline
\end{tabular}

According to the feedback from the questionnaire, most of the students generally agree with the mixed teaching model, and the satisfaction of the survey is more than $95 \%$. $97 \%$ of the students like this teaching method, and think that this kind of mixed teaching model is beneficial to the acquisition and mastery of knowledge, and helps to improve the ability of innovation.

\section{SUMMARY}

Students learn online at any time and place according to their acceptance and understanding. In the classroom, teachers and students interact in depth to discuss key and difficult issues.

The SPOC teaching model extends the traditional teaching time and space, extending from the traditional class to the pre class and after class, extending from the classroom to the network. From the pre class teaching, classroom teaching to after-school teaching, every step of the whole teaching process is the integration of online and offline teaching, and learning evaluation runs through the whole teaching process.

Make full use of rich MOOC resources and construction quality, construction of SPOC learning environment, the traditional classroom teaching and SPOC combination, to innovate the teaching process, teaching methods effectively Alto, improve the quality of teaching and learning.

\section{REFERENCES}

[1] 360 library. "Flipping classroom" teaching model http://www. 360doc. com/content/13 /125/21 /14070959 332145620. shtml. (In Chinese)

[2] Baidu encyclopedia. Micro lesson [DB/OL]. http://baike. baidu. com/view/5982553. htm. (In Chinese)

[3] Guo Yang. Based on the SPOC model design of mixed learning and flipping classes, [J]. Asia Pacific Education, 2016 (01): 105-106+102. (In Chinese)

[4] He Bin, Cao yang. SPOC: MOOC - based teaching process innovation [J]. China's Audio-visual Education, 2015 ( 03 ): 22 - 29. (In Chinese)

[5] Jiang yi, Fei hongxiao. MOOC - Based mixed teaching model design and application research [J]. Higher Education of Sciences, 2015 ( 03 ): 120-125. (In Chinese)

[6] Liu chunyan. Exploring the application mode of spoc in primary and secondary education - based on arcsde model [J]. Audio - Visual Education in China, 2015 ( 12 ): 120 - 125. (In Chinese)

[7] Huang guangfang, Wu Hongyan, Jin yifu. ubiquitous learning environment spoc effective teaching practice and research [J]. Audio Visual Education Research, 2016,37 ( 05 ): 50 - 57. (In Chinese)

[8] Sui Xin. Research on flipped classroom teaching mode based on SPOC [J]. Journal of Jilin Institute of Education, 2017,33 (05): 149-151. (In Chinese)

[9] Kang yeqin. Online education " post mooc era" - spoc analysis [J]. Tsinghua University Education Research, 2014,35 ( 01 ): 85 - 93.

[10] Luo jiutong. mixed learning perspective mooc innovative research: spoc case study? [J]. Modern Educational Technology, 2014,24 ( 07 ): 18 - 25. (In Chinese)

[11] Luo jiutong, sun Meng, gu Xiaoqing. mixed learning perspective mooc innovative research: spoc case study?[J]. Modern Educational Technology, 2014,24 ( 07 ): 18 - 25. (In Chinese)

[12] Yang Li.SPOC application model in the traditional university teaching [J]. In Modern Educational Technology, 2016,26 (05): 56-62. (In Chinese)

[13] Fox, A.. From MOOCs to SPOCs[DB/OL]. (2013-12-16)[2015-02-20]. http://cacm.acm.org/agazines/2013/12/169931-from-moocs-to-spocs/full text. 